\title{
Optimal Resource Allocation at the Blue Economy Type of Firms*
}

\author{
Katalin Hartung
}

This article attempts to model the optimal resource allocation and the definition of firm's internal transfer prices of aiming to minimise their environmental impact. The author defines the concept of zero waste principle, also referred to as the blue economy principle, with the help of the linear activity analysis model. She demonstrates that if the firm cannot operate the technology which applies the zerowaste principle, then a firm can realise profit only by polluting the environment. She also shows how the internal transfer price of a by-product can be quantified and can take both a negative or positive value as well; thereby, promoting an open market driven by the objective of the blue economy. Finally, she also demonstrates that shadow prices relating to emission constraints may serve as the basis for environmental penalties motivating firms to restrain from environmental pollution.

Journal of Economic Literature (JEL) codes: C65, Q56

Keywords: internal transfer price, resource allocation, environmental impact, zero waste principle, environmental penalty

\section{Introduction}

According to Ghisellinia et al. (2016) and Munck - Scheel (2016) it is a fundamentally important objective that the economic growth would be accompanied by lower environmental pressure. Consequently, production technologies causing minimal adverse effects on the environment and human health should become higher on the agenda, while, if possible, the total output would be utilised during the profitable operation of the company. In his study, Jaehn (2016) mentions that the concept of sustainable production appeared - only ten to twenty years ago - for managing the negative environmental consequences entailed by growth. By sustainable production, Jaehn means the trends supporting resource efficiency.

\footnotetext{
* The views expressed in this paper are those of the author(s) and do not necessarily reflect the offical view of the Magyar Nemzeti Bank.

Katalin Hartung is a research fellow at the Faculty of Business and Economics of the University of Pécs. Email: hartungk@ktk.pte.hu

I would like to thank István Bessenyei, assistant professor at the Faculty of Business and Economics of the University of Pécs for his professional insight to our joint research.

The Hungarian manuscript was received on 19 December 2016.

DOI: http://doi.org/10.25201/FER.16.3.98118
} 
Recently, companies are increasingly inclined to use new sustainable development trends at the firm level. Our article discusses in details the operation of the blue economy (Bocken et al. 2014; Pauli 1998) which strives to follow the zero-waste principle. Some existing theories, such as industrial ecology (Esty - Porter 1988), the zero-waste principle (Pauli 1997), and the biomimicry (Benyus 2002) have, to some extent, already formulated the core principles of blue economy. Despite these existing theories, the clearly new feature of blue economy is that it envisages the entire economy to function in harmony with the ecosystem (Pauli 2010). The starting point of this holistic approach, based on its original understanding, is that every company is intrinsically related to its environment, so any given economic system can be examined in its totality only together with its environment. Only with this approach can we come to know any given economic system and its components. Biomimicry is best following this principle, mainly on product level. The other theories are originally not holistic (in general their term also refers to this fact). It is generally true for every sustainability trend that they think in terms of circular patterns; thus, reducing the utilisation of mineral raw material and resource stocks and the businesses' direct environmental impact. According to the approach of the blue economy, companies consider waste as resource, providing some kind of an answer to handling environmental issues. The generated waste during firm's production process therefore can substitute the entire resource need of companies or a part of thereof, while they can reduce costs or can result in additional revenues. The literature review of Hartung (2016) reveals that the exact definition of the concept of blue economy is still not defined by the terms of mainstream economy in the literature to date and the optimal internal transfer pricing of by-products used in the course of production has not been clarified yet either. The blue economy also has enterprise level applications and thanks to its resource efficiency, companies following the principles of blue economy often form intra-or intercompany synergetic co-operations in order to create a more efficient circular structure. According to Ghisellinia et al. (2016) the strategy of a company operating based on the principles of the blue economy embraces cleaner production and ecologically minded planning. Khalili et al. (2015) and Ghisellinia et al. (2016) pointed out that cleaner production has the fundamental benefit of being resource efficient. It deals with the reduction of waste and harmful emission in the course of product and process design at the enterprise-level. It supports integrated and preventative environmental strategies in order to create equilibrium between the company and the environment. Klemes et al. (2012) supports that cleaner production will become an increasingly important tool for every industrial player. In the experience of Genovese et al. (2015), in addition to end-of-pipe solutions, businesses now place increasing emphasis on monitoring and improving the impact they have on the economy, the environment and society throughout the lifecycle of the entire product or service. According to the research of $\mathrm{Li}-\mathrm{Su}$ (2012) the circular economy strives to sustain human and environmental equilibrium by more efficiently utilising natural resources. In addition, the circular economy defines production processes. By this we mean that the firm operates in a closed system where the waste kept within the system replaces 
the possible need for mineral and natural resources. Li and Su (2012) observed that businesses using the circular economy approach typically had lower initial investment costs, they minimised their emission of industrial contaminants while using their available stocks to the maximum and exerted the least possible negative effect on the environment. In his research, Pauli (1998) calls attention to the fact that a company is unable in and of itself to comply with the zero-waste principle; consequently, he considers the trading of by-products among companies as indispensable. Therefore, cooperation among companies is a key component of the principle of blue economy encouraging that the by-product generated during the production of one company be used as raw material, as semi-finished product or as processing aid in the production process of the other company.

The valuation of by-products (semi-finished products, waste or contaminants) reused within the company or purchased from a partner company is far from being properly regulated when it comes to business operations. These transactions are sold at an internal settlement price, the so-called transfer price that influence the companies' expenses and profit. It is clear that transfer prices are not defined by the rule of supply and demand, but mainly by the intention to minimize payable taxes, tax type budgetary contributions and customs duties. (Gao - Zhao 2015). In the international context, a study prepared by the OECD ${ }^{1}$ provides guidance for companies regarding the setting up of their internal transfer pricing while in Hungary, Act LXXXI of 1996 on corporate taxation and dividend tax provides guidance on the rules for tax base adjustment needed when transfer pricing is applied within the network of companies or when the pricing applied among independent parties deviate from current market prices. Ding et al. (2015) analysed as to what happens when the costs of a company stemming from its negative impact on the environment (input and output) show up in its accounting. In their research, they examined the optimal pricing of sustainable supply chains using quantitative methods, namely they tried to internalize environmental externalities. They studied the differences of the various pricing options (decentralized, centralized or specific pricing options applicable among the different units) and the driving forces influencing the players of the supply chain and finally the role of enterprise incentives used by governments. The authors concluded that the literature hardly mentions any such cooperation, which would motivate the players of the sustainable supply chain to make investments aimed at reducing polluting waste or the trading of by-products (such as pollutants). In their article, Lakatos - Karai (2015) sought to answer the question of how the evolution of market prices, the specifics of the Hungarian Accounting Act and the existence of affiliated corporate relations influence the procurement and the trading of carbon credits. Their literature review reveals that the accounting classification of emission units has been answered,

${ }^{1}$ Transfer Pricing Guidelines for Multinational Enterprises and Tax Administrations. OECD, 2010, ISBN 97892-64-09018-7 
but corporate taxation and the related transfer pricing issues of carbon credit trading remained uncharted territories. In their conclusion, the transfer pricing of carbon credits is not exempt from the obligation to apply the market price. If the affiliated companies deviate from market pricing, they have to adjust their corporate tax base accordingly. According to Kuti (2014) it is not always possible to quantify the financial significance of social and environmental externalities for investment purposes and on the other part, due to the discounting of long-term expenses and impacts, these externalities become marginal. We disagree with this latter statement since in our view the impact of companies on the environment is substantial even in the longer run.

Moreover, literature on the fines for environmental penalties levied for polluting companies is still rather immature. According to Karpoff et al. (1998) the levied environment pollution fines do not correlate with the extent of the pollution. In their experiences, these penalties are rather varied and unpredictable. However, they managed to identify some correlation between the price reduction of a company shares caused by pollution and the magnitude of the penalty. A 2009 study of the OECD analyses the rules applied to fining environmental pollution in Eastern European, Caucasian and Central Asian countries. It reveals from the study that the regulation is rather incomplete in many countries. The meaning of some basic concepts frequently remains unclarified, such as environmental fine, environmental charge and environmental damage or the concept of compensation. However, we see some similarities among the countries mentioned by the OECD (2009) study and Germany in terms of the factors mitigating the penalty. If the perpetrating company previously performed some environment protection activity, but the environmental pollution occurred nonetheless, then the extent of the imposed fine is reduced (Schelmminger - Martens 2004). But the scale of the penalty varies country by country. In Eastern European and Caucasian countries, the fine levied for emission exceeding the permitted level depends on the quantity and harmfulness of the emitted polluting substance. In Kazakhstan, the fine imposed for environment pollution is determined exclusively based on the extent of the damage caused by the company. By contrast, the German criminal law may impose financial penalty and/or prison sentence (Schelmminger - Martens 2004).

In view of the above-mentioned lack of coverage in the literature, the purpose of this study is to define blue economy businesses by using firm's model minimizing adverse effects on the environment, as well as the internal transfer pricing of by-products (contaminants) and to suggest the proposed scale of environmental penalties. To this end, we shall use the linear activity analysis model applied in the article of Bessenyei (2016). The linear activity analysis model (LAM) is used for optimal resource allocation problems enabling the selection of technologies and the application of production of multiple products at a time (Zalai 2012). The significance of multiple products' production appears when incorporated into the by-product and pollutant emissions 
into the model, since the LAM model is able to illustrate the flow of by-products and semi-finished products generated in the course of production. Presenting the technology choice is indispensable in the blue economy, since each technology pollutes the environment differently. The linear activity analysis model treats the emission of various polluting substances separately, which makes it possible to take into account that a specific technology emits more of type " $A$ " polluting substance, while another technology emits more of type "B" pollutants. Some other, more complicated models are also suitable to formulate this problem, but those are beyond the framework of this article. Let us also assume, based on the above-mentioned remarks of Pauli (1998), the market and technology openness where the environmental protection strategy aspects also play a central role.

The second section of the study briefly presents the LAM methodology. The third section presents the firm-level application of the environmental friendly strategy, namely the firm-level application of the blue economy principle within the methodology framework of the linear activity analysis model. This section reveals the correlation between the shadow price and the internal transfer price and determines the basis for imposing the environmental penalty. The fourth section presents the operation of the quasi blue economy type of firm who is unable to follow the principles of the blue economy, but who strives to minimise its environmental impact in the LAM context. Finally, the study concludes with the presentation of future research directions and conclusions.

\section{Methodology}

Corporate value creation takes place through the application of activities or processes that are possible technically and operation-wise ${ }^{2}$, though the intensity and the level of application may differ. As mentioned earlier, the tool of the linear activity analysis model is perfectly suitable for describing the flow of by-products among the different activities and later on also for defining the blue economy principle. Accordingly, this section briefly presents the basic structure of the LAM model.

A given production unit produces products and/or services. As part of this, it uses products and services produced by the firm, and the resources purchased on the market, such as labour, water, electricity, etc. For the sake of simplicity, we shall refer to the service produced by the company as product.

Let the company have $n$ types of products, also including semi-finished and byproducts and services and wastes. To produce these, let the company use $N$ types of primary resources! Let $R_{+}$designate the set of nonnegative real numbers, then any core technology can be described with the help of the following three

\footnotetext{
${ }^{2}$ Zalai (2012) refers to these activities or processes as primary or core processes.
} 
vectors: $\mathbf{k} \in R_{+}^{n}$ is the vector of output coefficients, $\mathbf{r} \in R_{+}^{n}$ is the vector of input coefficients while $d \in R_{+}^{n}$ is the vector of primary resource utilisation coefficients. The components of the three vectors indicate the necessary and produced product and input requirements necessary during the unit level operation of the basic technology. The intensity of the given activity can be expressed by any natural unit. This could be, for example, the operating duration of the activity or the quantity of some of the primary resources (for example electricity) utilized for the activity.

Let us note that vector $\mathbf{k}$ generally has more positive elements, since during most processes, in addition to products suitable for further processing or sale, some byproducts, wastes or polluting substances are also generated. If every component of vector $\mathbf{k}$ is zero, then the purpose of the given activity is to neutralize pollutants. But the process of neutralization is rarely perfect; therefore, there are always some positive components. If free removal is not available, that is, unsellable wastes or pollutants cannot be removed from the system free of charge, then the $\mathbf{y}^{\mathbf{p}}$ variable must be introduced describing the emission into the environment of the pollutants created during the joint operation of the various activities, including the emission of waste as well. If vector $\mathbf{k}$ has several positive elements designating the produced quantity of products suitable for sale or further processing, then we talk about production of multiple products. Vector $\mathbf{y} \in R_{+}^{n}$ describes customer demand. The elements of this vector indicate for the production manager the quantity to be produced of each product. For those semi-finished and by-products, processing aids, wastes and services for which there are no customer demand, the corresponding component of vector $\mathbf{y}$ is zero, although the firm also produces these. Because we assume market openness, the company may sell for its partner firms the positive elements found in vector $K \underline{\mathbf{x}}$ the quantity of which is found in vector $\mathbf{z}$. Furthermore, the company may also procure intermediary- and semi-finished products on the market from partner firms if these partner firms produce them more efficiently. Vector $\mathbf{u}$ describes the quantity of these products.

If every element of vector $\mathbf{r}$ is zero, then the given basic technology uses only primary resources; the semi-finished products, processing aids, wastes and services produced by the company are not needed for the basic technology. Vector $\mathbf{d}$ has only zero elements less frequently, because most technologies use some kind of primary resources.

But of course, most companies are able to engage in more than one basic technology. These basic technologies are described by vector $\underline{\mathbf{x}} \in R_{+}^{m}$. Let the number of activities technically and operationally available be $m$. Each of these can be described with the above introduced three vectors, so the following matrices can be created:

- The matrix of output coefficients: $\mathbf{K}=\left(\mathbf{k}_{1}, \mathbf{k}_{2}, \ldots, \mathbf{k}_{\mathrm{m}}\right)$, where $k_{i j}$ shows how much of product $i$ is being produced by the per-unit application of activity $j$. 
- The matrix of input coefficients: $\mathbf{R}=\left(\mathbf{r}_{1}, \mathbf{r}_{2}, \ldots, \mathbf{r}_{\mathrm{m}}\right)$, where $r_{i j}$ shows how much of product $i$ is being produced by the per-unit application of activity $j$.

- The matrix of primary resource utilisation coefficients: $D=\left(\mathbf{d}_{1}, \mathbf{d}_{2}, \ldots, \mathbf{d}_{\mathrm{m}}\right)$, where $d_{l j}$ shows how much is needed from the primary resource $/$ for the per-unit application of activity $j$. The above described processes are summarized in Figure 1.

\section{Figure 1}

Explanation of the operation of a production firm with the help of the LAM marking system.

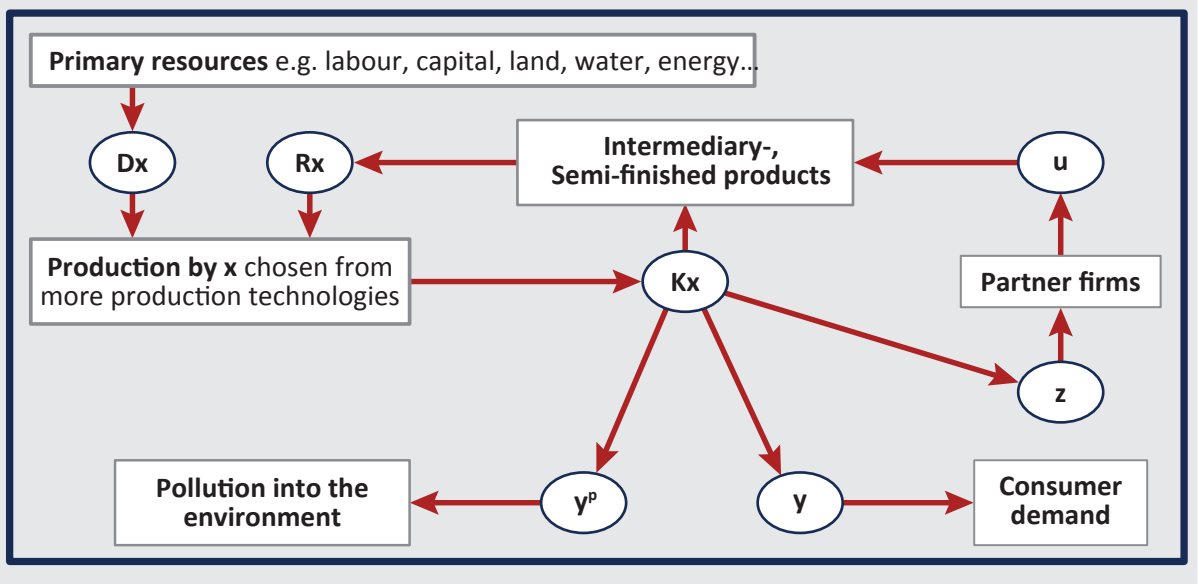

In the linear activity analysis model, these three matrices define the firm's technological possibilities. Technical management and engineers have information about the exact value of their elements which must be in line with the data that can be obtained from the firm's accounting system. It is worth noting that if there is more than one positive component in line $i$ of the matrix of output coefficients, then the firm is able to produce product $i$ through several activities. In such case, we are talking about technological selection. In this case, the role of the linear activity analysis is the selection of the appropriate technological combination.

We define the optimal task of the linear activity analysis model in the following way: Let the customer demand be given $\left(\mathbf{y} \in R_{+}^{n}\right)$. The net output results from the difference of the $\mathbf{K} \underline{\mathbf{x}}$ product output and the $\mathbf{R} \underline{\mathbf{x}}$ product utilization, which, according to the constraint, should be at least $\boldsymbol{y}$ of the customer demand. The product equilibrium of the firm is expressed in the model with the following equation: $(\mathbf{K}-\mathbf{R}) \mathbf{x} \geq \mathbf{y}$. Furthermore, let the stock of the primary resources be $\underline{\mathbf{s}}$. The primary resource utilisation of the firm is expressed by the matrix $\mathbf{D} \underline{\mathbf{x}}$. Let us assume that the firm uses less primary resources than the available quantity. Then the resource balance will be as follows: $\mathbf{D x} \leq \mathbf{s}$. Assuming these conditions and the condition of 
$\underline{\mathbf{x}}$ non-negativity, we are looking for the production level at which the cost is the lowest or the revenue is the highest.

To resolve this problem we recommend using the GAMS (General Algebraic Modelling System) software, providing for the user a high-level programming language expressly developed to resolve problems of this nature presented in the following part of the study. The classroom version of this software can be downloaded free of charge on the Internet.

\section{Environmental friendly strategy, namely firms blue economy principle}

In the section below we shall present the operation of a production firm within the framework of the LAM methodology, where environmental protection strategy and, in the current case, the principle of the blue economy play an emphatic role in the life of the firm. Moreover, the interpretation of the primal and dual problems of the LAM model provides some guidance for defining the environmental penalty and internal transfer prices.

In addition to the products suitable for further processing and satisfying customer demands, most production activities performed by firms also produce by-products as well as wastes or pollutants harmful to the environment. According to Georg et al. (2015), production processes of the market economy result not only in the end product, but also produce unwanted waste the elimination of which entails expenses for the firm. This has also been confirmed by Dobos (2008) who adds that by-products cannot be removed from production. But the problem is that these goods are not indicated in the production plan. Hartung (2016) notes that the recognition of Dobos (2008) is significant, since the utilisation opportunities of by-products generated in the course of production becomes impossible as the business designer is not aware of their existence. The situation is the same in the case of wastes and polluting substances. Let us now also include these items in the list of goods ${ }^{3}$. Let $\overline{\mathbf{y}}$ denote the quantity of unsold products that can be emitted into the environment. The amounts included therein can be defined by both the firm's environmental protection strategy and the environmental protection authority. However, according to Dobos (2008), the legal obligation in and of itself does not necessarily mean a binding force for the firms, since in many cases firms often opt for the more easily payable fine (depending on its extent).

When a firm strives to comply with the zero-waste principle, it must be open not only to its customers, but also to other firms as well. It results from the principle of the blue economy mentioned in the introductory section that semi-finished

\footnotetext{
3 "The precondition for describing a technology. This description presents the goods occurring in the possible production activities of the examined unit, presenting a comprehensive list of such goods free from any overlap" (Zalai 2012:72).
} 
products, processing aids and production services should not only be produced by the firm itself, but in addition to or in place thereof, it should also be possible to procure these items from the market. So next to the semi-finished products produced by the firm, semi-finished products procured from the market also appear. Vector $\mathbf{u}$ describes the quantity of these products. If the company does not have sufficient capacity, it may happen that for $i$ product $0<y_{i} \cdot u_{i}$, where $y_{i}$ is the customer demand for product $i$. This means that the firm satisfies part of its customer demands not from its own production, but procures the finished product from the market and directly sell to the customer. But in general this is not the case, and instead $\forall i=1, \ldots, n: 0=y_{i} \cdot u_{i}$, namely if the firm procures some products from the market, then it does not sell such products.

The environmental friendly strategy - just as the blue economy principle - requires the elimination of spendthrift activities, but also the sale of every by-product, waste and possibly contaminants for which there is solvent market demand, or alternatively, these items could be more efficiently neutralized by other companies. This market openness towards other companies is of fundamental importance. If beyond satisfying customer demands, resource management is efficient, then the firm's negative impact on the environment is also reduced. In our model, the quantity of products transferred to partner firms is described by vector $\mathbf{z}$. In the spirit of market openness, the firm mostly sells products for which there is customer demand $\left(z_{i} \cdot u_{i}=0\right)$, and does not buy this product from the market $\left(z_{i} \cdot u_{i}=0\right)$. We will see later that this openness creates the link between market prices and the internal transfer prices of the products produced to satisfy customer demands.

We assume that in the course of utilizing the opportunities stemming from market openness, the firm is unable to influence the prices and it may procure the various products at the prices described by vector $\mathbf{p}^{m}$, and can sell these products at the prices described by vector $\mathbf{p}^{\mathrm{e}}$. For the sake of generalization, we assume that $\mathbf{p}^{\mathrm{e}} \leq \mathbf{p}^{\mathrm{m}}$. Based on these we can say that in the course of utilizing the opportunities stemming from market openness, the firm incurs losses equal to $\mathbf{p}^{\mathrm{m}} \mathbf{u}-\mathbf{p}^{\mathrm{e}} \mathbf{z}$, and it may finance such losses with the help of a working capital loan. We consider negative losses as profit, reducing the need for working capital financing. The extent of such working capital financing is limited by the value $d_{e}$ defined by the firm's financing conditions. In the case of $0<d_{e}$ it is permitted that in the course of utilizing the opportunities stemming from market openness, the firm incurs losses up to the limit, and in the case of $0>d_{e}$ it must attain profit at least of the extent defined by the limit. Less frequently the $0=d_{e}$ equilibrium criterion is also prescribed for the firm.

Let $\overline{\mathbf{s}}$ denote the existing quantity of the primary resources available for the firm. These mostly include capital assets, machinery, equipment, fixtures and workers. This primary resource quantity must be supplemented to the extent so as to satisfy customer demands. The additional primary resource quantity thus being procured 
is described by vector $\mathbf{s}$. The validity of $s_{i} \cdot \overline{s_{i}}=0$ is not true in general, instead, the stock of existing primary resources must be expended. We assume that the firm does not have a dominant position on the resource market either. Then, the prices of primary resources are the constants that the firm is not able to influence, contained in vector $\mathbf{q}$. Because customer demands are given, and as such, the firm's revenues are also given, the profit may only be increased through reducing the cost of the primary resources to be procured additionally. The magnitude of this expense is defined by the qs scalar multiplied.

The primal task of the firm applying the environmentally friendly strategy, as opposed to the LAM task presented in the methodology, evolves as follows:

$$
\begin{array}{rlrl}
\mathbf{x}, \mathbf{z}, \mathbf{y}^{\mathfrak{p}}, \mathbf{s}, \mathbf{u} & \geq 0 \\
(\mathbf{p}) & \mathbf{R} \mathbf{x}+\mathbf{y}+\mathbf{z}+\mathbf{y}^{\mathbf{p}} & =\mathbf{K} \mathbf{x}+\mathbf{u} \\
(\mathbf{w}) & \mathbf{D} \mathbf{x}-\mathbf{s} & \leq \overline{\mathbf{s}} \\
(v) & \mathbf{p}^{\mathrm{m}} \mathbf{u}-\mathbf{p}^{\mathrm{e}} \mathbf{z} & \leq d_{e} \\
\left(\mathbf{t}^{y}\right) & \mathbf{y}^{\mathrm{p}} & \leq \overline{\mathbf{y}} \\
-\mathbf{q} \mathbf{s} & \rightarrow \max
\end{array}
$$

In front of each condition we indicated in brackets the dual variables belonging to them, also called as shadow prices ${ }^{4}$ for which we will provide the explanation later on. Conditions (1) of the primal problem provide limitations for the sign of the variables. Conditions (2) are the product equilibrium where the conditions of equilibrium are met on the market of products and resources. Conditions (3) are the primary resources equilibrium. Conditions (4) are the equation describing the maximum loss allowed, incurred during the sales of the by-products, wastes and polluting substances, where $d_{e}$ may take either a positive or zero value, but through $0<d_{e}$ a profit may also be realised. Equations (5) yield the quantity of products that can be emitted into the environment. And finally, equation (6) is the objective function maximizing profit.

The following are given during the resolution of the primal problem: the $\mathbf{K}, \mathbf{R}$ and D matrices describing the production technology of the firm; the firm's supply of primary resources $\overline{\mathbf{s}}$; the magnitude of maximum achievable loss in the course of the opportunities stemming from market openness $d_{e}$; q denoting the market procurement prices of primary resources; and $\mathbf{p}^{m}$ denoting the procurement price of the firm's products and $\mathbf{p}^{\mathrm{e}}$ the sales price of the firm's product.

\footnotetext{
4 "The dual solutions of the linear optimal resource allocation tasks are called shadow prices. They are the opportunity costs of goods and resources featured in the restrictive conditions expressed in the objective function value. They express how much the last unit of the goods available from external resources contribute to the objective function value" (Zalai 2012:84).
} 
The resolution of the primal problem yields: the application level of each activity $\mathbf{x}$, the quantity of the primary resources to be procured additionally $\mathbf{s}$, the quantity of the products to be procured and to be transferred through market openness $\mathbf{u}$ and $\mathbf{z}$, and shadow prices $\mathbf{p}, \mathbf{w}, v$ and $\mathbf{t}^{\mathrm{y}}$.

Interpretation of the shadow prices appertaining to the various conditions:

(p) The shadow price of a product shows to what extent the cost of the primary resources to be procured additionally would be reduced if customer demand of a given product was reduced by a certain unit: $p_{i}=\delta \mathbf{q s} / \delta y_{i}$. If this value is lower than what the customer is willing to pay for the given product, then the customer demand for the given product could only be satisfied with a loss.

(w) The shadow price of the primary resource shows the extent to which the cost of the primary resource to be procured additionally would be reduced if the firm had more units of the given resource and it did not have to procure it: $w_{i}=\delta$ qs $/ \delta \bar{s}_{i}$. If this value is zero, then, in line with duality, the additional procurement of the given primary resource is unnecessary.

(v) The shadow price of the loss incurred in the course of market openness shows the extent to which the cost of the primary resources to be procured additionally would be reduced if this loss is increased by one unit: $v=\delta \mathrm{qs} / \delta d_{e}$.

$\left(\mathbf{t}_{i}^{y}\right)$ The shadow price related to the output limit shows by how much the objective function value would improve, namely the extent to which the firm's profit would increase if the emission of product $i$ into the environment increased by one unit. This value is a good indicator for defining the environmental protection penalty to be imposed for exceeding the emission constraints. Moreover, this definition procedure helps to resolve the unpredictability and differences surrounding environmental protection penalties mentioned in the literature.

Therefore, the objective of the firm is to produce a given emission of $\mathbf{y}$ so that the cost of the primary resources to be procured additionally be minimal by adhering to the environmental protection conditions prescribed by vector $\overline{\mathbf{y}}$. In the case of $\overline{\mathbf{y}}_{i}=0$ it is a semi-finished product, by-product or waste to be further processed.

We obtain the internal transfer prices as the solution of the dual problem of the firm applying the environmentally friendly strategy ${ }^{5}$. The Appendix contains the simplex table necessary for expressing the duality:

\footnotetext{
5 "The shadow price of intermediary products not having a market and the shadow price of primary resources is the firm level internal transfer price defined by their opportunity costs. The internal transfer or accounting price is similar to the shadow price in many respects" (Zalai 2012:104).
} 


$$
\begin{aligned}
\mathbf{w}, v, \mathbf{t}^{y} & \geq 0 \\
\mathbf{p}(\mathbf{K}-\mathbf{R}) & =\mathbf{w D} \\
\mathbf{w} & \leq \mathbf{q} \\
\mathbf{p} & \leq v \mathbf{p}^{\mathrm{m}} \\
\mathbf{p} & \geq v \mathbf{p}^{\mathbf{e}} \\
\mathbf{p}+\mathbf{t}^{y} & \geq 0 \\
\mathbf{w} \overline{\mathbf{s}}+v \cdot d_{e}+\mathbf{t}^{\vee} \overline{\mathbf{y}}-\mathbf{p y} & \rightarrow \min
\end{aligned}
$$

Our firm will opt for the $\underline{\mathbf{x}}$ activity combination ensuring minimal primary resource costs and thus ensuring maximum profit if it applies the internal transfer prices obtained as the result of this problem solved.

In this case, the dual variables of the dual problem, that is, the variables of the primary problem here stand after the conditions. It is worth drawing attention to the fact that we do not apply any restrictions whatsoever to the signs of the $\mathbf{p}$ variables due to the equality condition featured in the primal problem. Accordingly, the internal transfer price of certain products may also be negative. However, according to conditions (11) and (12) it is necessary that the sales price of the given product be negative. This is exactly the case when it comes to polluting substances, as our firm may purchase these at a negative price, namely it is the partner firm who pays for taking them over. In this case, it is our firm who will take care of the dumping, processing and destruction of the polluting substances taken over. As for those polluting substances in the case of which our firm does not perform such activities, it may transfer these polluting substances to be destroyed to other firms. However, in this case, it is our firm who will pay for transferring them.

Interpretation of conditions of the duality problem:

(8) It describes the correlation between the internal transfer price of primary resources and the internal transfer price of products.

(9) It describes the correlation between the internal transfer price and the market price of primary resources. It is to be noted that if the firm purchases one of the primary resources, then this condition shall be met in the form of equality. Therefore, the internal transfer price of a product depends on the market price of the primary resources, which confirms the result of the research conducted by Lakatos - Karai (2015) as discussed in the introductory section.

(10-11) If the firm transfers some by-product or waste to another firm, then its internal transfer price is proportional to the price applied during the transfer which may also be negative, for example, in case of waste neutralization. If the firm takes 
over some by-products or waste, the internal transfer price will also be proportional to the price applied during the transfer.

(12) If $p_{i}<0$, then $t_{i}^{y}>0$. Accordingly, if a product has a negative internal transfer price, then with the increase of $\bar{y}_{i}$ the objective function value of the primal problem would improve because the firm would reach the $\bar{y}_{i}$ limit of environmental emission of the given pollutant!

Moreover, in view of duality, the objective function value of the dual and primal problem is identical:

$$
\mathbf{w} \overline{\mathbf{s}}+v \cdot d_{e}+\mathbf{t}^{\mathrm{y}} \overline{\mathbf{y}}-\mathbf{p y}=-\mathbf{q} \mathbf{s}
$$

of which

$$
\mathbf{w} \overline{\mathbf{s}}+\mathbf{q s}+v \cdot d_{e}+\mathbf{t}^{y} \overline{\mathbf{y}}=\mathbf{p y} .
$$

The sales revenue stemming from satisfying customer demands stand on the right side of equation (15). This has to finance the cost components on the left side. These are the following by order:

- $\mathbf{w} \overline{\mathbf{s}}$ the cost of financing the primary resources already available at the firm,

- qs the cost of primary resources to be procured additionally,

$-v \cdot d_{e}$ the loss incurred in the course of selling by-products, wastes and polluting substances,

$-\mathbf{t}^{\mathrm{y}} \overline{\mathbf{y}}$ the loss incurred by limiting the emission of harmful materials into the environment.

Considering the comment related to condition (9) of the dual problem, we can say that the firm does all of this by calculating at internal transfer prices.

The correlations existing between the market price and the shadow price of a product result from the dual task. Let us assume for a second that $\mathbf{p}^{\mathbf{m}}=\mathbf{p}^{\mathbf{e}}$ ! In this case shadow prices are proportional to the market prices and the proportionality factor is: $v$. If $\mathbf{p}^{\mathbf{m}} \neq \mathbf{p}^{\mathrm{e}}$, then the shadow price of the product that the firm purchases will be proportional to its procurement price while the shadow price of the product that the firm sells as by-product or waste will be proportional to its sales price. The proportionality factor remains $v$. And if $u_{i}+z_{i}=0$, that is, if the firm does not purchase certain products but only sells them to satisfy customer demand, then $v p_{i}^{m}<p_{i}<v p_{i}^{e}$ is valid for its shadow price.

We can talk about blue economy if the above task has an admissible solution if $\overline{\mathbf{y}}=0$, since the model shows the most important criteria of the blue economy principle: the integration of semi-finished and finished products into production; the sales of 
by-products and polluting substances among companies ( $\mathbf{z}$ ) and (u); instead of the customarily used inequality (e.g. Zalai 2012) equality has been introduced into the product equilibrium; and adherence to the zero waste principle-based production $(\bar{y}=0)$. However, the latter is usually not possible in this form and as a result of the proportionality of the linear activity analysis model, satisfying customer demands at a lower level, that is, reducing the components of $\mathbf{y}$ does not help either.

\section{The quasi blue economy type of firm}

This section presents the operation of the quasi blue economy type of firm who is unable to follow the principles of the blue economy, but who is striving to minimise its negative environmental impact. We shall see that in the lack of a technology necessary to comply with the zero-waste principle, the firm may realize profit only by impacting the environment negatively.

In order to obtain a model that is applicable for a firm approaching the principles of the blue economy, the firm must give up its profit maximizing behaviour, and instead, it must strive to minimize its negative environmental impact. Although the firm is unable to maintain its output in line with the zero-waste principle, but it can reduce the quantity of primary resources taken from the environment and the volume of polluting substances emitted into the environment. Account taken of this, the primary problem of a quasi-blue economy type firms evolves as follows:

$$
\begin{array}{rlrl}
\mathbf{x}, \mathbf{z}, \mathbf{y}^{\mathrm{p}}, \mathbf{s}, \mathbf{u} & \geq 0, \\
(\mathbf{p}) & \mathbf{R} \mathbf{x}+\mathbf{y}+\mathbf{z}+\mathbf{y}^{\mathbf{p}} & =\mathbf{K} \mathbf{x}+\mathbf{u} \\
(\mathbf{w}) & \mathbf{D} \mathbf{x}-\mathbf{s} & \leq \overline{\mathbf{s}} \\
(v) & \mathbf{p}^{\mathrm{m}} \mathbf{u}-\mathbf{p}^{\mathrm{e}} \mathbf{z} & \leq d_{e} \\
-\mathbf{r} \mathbf{y}^{\mathbf{p}}-\mathbf{q} \mathbf{s} & \rightarrow \text { max. }
\end{array}
$$

From the primal problem presented in section 3, on the one part, we omitted the condition limiting the emission of polluting substances as the firm is unable to operate with zero emission. On the other part, the minimizing of negative environmental impact stemming from the emission of polluting substances and the utilisation of primary resources is now part of the objective function.

Namely, the firm's emission of polluting substances and its utilisation of primary resources (freshwater, other renewable and non-renewable natural resources) are the items impacting the environment. The first is aggregated by the weighted amount $\mathbf{r y} \mathbf{p}^{\mathrm{p}}$, where $r_{i}$ quantifies the negative environmental impact stemming from the emission of one unit of product $i$ as polluting substance into the environment. On the other part, $q_{k}$ contrary to the previous section, is not the procurement price of primary resource $k$, but instead, it shows the extent of negative environmental 
impact caused by the utilisation of a primary resource of type $k$. Accordingly, the profit maximizing objective of the firm as explained in section 3 is now replaced the by an objective function minimizing negative environmental impact. This, however, cannot be regarded as a business operation fully adhering to the principles of the blue economy, but it is approximating it since $\mathbf{y}^{\mathfrak{p}} \geq 0$ is permitted.

The dual problem obtained based on the table of the (16-20) simplex problem (the Appendix contains the simplex table necessary for expressing duality):

$$
\begin{aligned}
\mathbf{w}, v, \mathbf{t}^{y} & \geq 0, \\
\mathbf{p}(\mathbf{K}-\mathbf{R}) & \leq \mathbf{w D} \\
\mathbf{w} & \leq \mathbf{q} \\
\mathbf{p} & \leq v \mathbf{p}^{\mathrm{m}} \\
\mathbf{p} & \geq v \mathbf{p}^{\mathbf{e}} \\
\mathbf{p} & \leq-\mathbf{r} \\
\mathbf{w} \overline{\mathbf{s}}+v \cdot d_{e}-\mathbf{p y} & \rightarrow \min .
\end{aligned}
$$

Opting for the combination of activities $\underline{\mathbf{x}}$ resulting in minimal negative environmental impact will be the rational choice for our firm if it applies the internal transfer prices obtained as the solution of the problem.

According to condition (27), if a certain polluting substance is being emitted, then its internal transfer price is equal to the additional negative environmental impact stemming from the emission of one unit according to the definition of $\mathbf{q}$. The situation is similar for primary resources as well. If the firm procures some kind of primary resource, then its internal transfer price will also be equal to the additional negative environmental impact stemming from utilization. Moreover, if there is emission of polluting substance $i$, then $p_{i}=r_{i}$, and if the firm transfers part of this polluting substance to another firm, then $p_{i}=-r_{i}=v p_{i}^{e}$. So, based on this $p_{i}, p_{i}^{e}<0$ and $v=-r_{i} / p_{i}^{e}$, that is $v$ can be interpreted as the "exchange rate" of the negative environmental impact due to the emission of polluting substances. An even more interesting case is when the firm purchases polluting substances from another firm and emits them into the environment. This can serve the minimizing of the objective function and the reduction of the negative environmental impact if the polluting substance is taken over at a high $p_{i}^{m}$ price because then the $\mathbf{p}^{\mathrm{m}} \mathbf{u}-\mathbf{p}^{\mathrm{e}} \mathbf{z}$ difference improves significantly, enabling the financing of additional activities aimed at reducing negative environmental impact. In this case $p_{i}=-r_{i}=v p_{i}^{m}$, and it can be interpreted as $v=-r_{i} / p_{i}^{m}$, as the "exchange rate" of the negative environmental impact. This case does not happen if vector $\mathbf{r}$ is identical for every firm, but $\mathbf{u}$ is not necessarily a zero vector in this case either, as our firm may 
have the technology which is able to transform the waste generated by another firm into a product satisfying customer demands or utilize them in the course of neutralization. Accordingly, the basis of the internal transfer prices applied by the firm is the negative environmental impact stemming from the utilisation of natural resources and the emission of polluting substances.

Moreover, the duality results in the equality of the objective function value of the dual and primal problem:

$$
\mathbf{w} \overline{\mathbf{s}}+v \cdot d_{e}-\mathbf{p y}=-\mathbf{r y} \mathbf{p}^{\mathbf{p}}-\mathbf{q s},
$$

of which

$$
\mathbf{p y}-\mathbf{w} \overline{\mathbf{s}}-v \cdot d_{e}=\mathbf{r y}{ }^{\mathbf{p}}+\mathbf{q s} .
$$

On the left side of equation (29) we have the sales revenues stemming from the satisfaction of customer demands minus the cost components. This finances the negative environmental impact shown on the right side.

Notes

1. The firm generates profit (if and when this is the case) not because its objective to maximize its profit, but so that it can satisfy customer demand with minimal negative environmental impact.

2. We took into account the cost of primary resources procured additionally as negative environmental impact.

3. If the firm is able to satisfy customer demand with zero negative environmental impact (in the case of an optimal solution the objective function value of the primal problem is zero), then it will not realize any profit.

Point 3 presents the main result of the study. Based on this, a firm may become profitable only by impacting the environment. This means, however, that blue economy companies cannot be profitable. Our result is similar to the theory of land rent according to which the scarcity of natural resources (land) results in lasting economic profit (Barancsuk 2012:279). This is the rent which is acquired by the owner of the natural resource.

\section{Conclusions and future research directions}

In our study, we modelled the optimal resource allocation of companies respecting their embeddedness into the natural environment with the help of the linear activity analysis framework. In the third section, we reviewed the conditions of a business respecting the principles of the blue economy and incorporated them into the 
linear activity analysis model. Within the LAM model we defined a profit maximizing objective, accompanied by $\overline{\mathbf{y}}=0$ zero pollutant emission. In the dual problem, we demonstrated that internal transfer prices may be both negative and positive, enabling the transfer and the taking over of polluting substances. Moreover, we demonstrated that shadow prices linked to emission constraints may serve as the basis for efficient environmental penalty. To this end, we must know the $\mathbf{K}, \mathbf{R}$, D matrices describing the production technology of the firm and the $\overline{\mathbf{s}}$ vector describing the firm's primary resource supply.

In the fourth section, we defined a quasi-blue economy type enterprise model within the framework of the LAM, minimizing the negative environmental impact in the event the firm is unable to comply with the strict zero waste principle. The minimizing of negative environmental impact stemming from the utilisation of primary resources and the emission of polluting substances became part of the objective function. The main result of the study is obtained from the dual problem according to which any firm may become profitable only if it impacts the environment; consequently, blue economy type companies cannot be profitable. Moreover, the basis of the internal transfer prices applied by the firm is the negative environmental impact stemming from the utilisation of natural resources and the emission of polluting substances.

Defining a function that is aggregating the environmental pressure emerges as a future research direction, since defining the level of environmental pressure through the application of the $r \mathbf{y}^{\mathbf{p}}+\mathbf{q s}$ linear cost function is not always appropriate given the fact that the emission of certain polluting substances is not always proportional to the resulting negative environmental impact. Although the references found so far in the literature assume a linear connection between the emission of polluting substances and their impact on the environment (Wenzel et al. 1997; Potting - Hauschild 1997; Brink et al. 2001; Abdullah 2014), it would make sense to assume that in certain cases the situation is worse than that: if the emission of polluting substances is increased to $\lambda$-fold, the resulting environmental pressure usually increases by more than $\lambda$-fold. In order to model this problem, we must give up the linear objective function and apply the following convex function instead:

$$
f\left(y^{p}, s\right)=\sum_{i=1}^{n} r_{i}\left(y_{i}^{p}\right)^{\alpha_{i}}+\sum_{k=1}^{l} q_{i}\left(s_{k}\right)^{\beta_{k}}, \text { where } \alpha_{i}, \beta_{k} \geq 1 \text {. }
$$

The conditions of the model define a convex polyhedron and because the cost function is convex, the local solution may well be a global one, and consequently we do not expect more serious mathematical problems.

According to Kuti (2014) sustainability represents numerous risks and opportunities for companies. These risks include infringement fines, waste management, 
increasing competition for scarce resources, and the increasing expenses thereof. Opportunities include improving operating efficiency, better risk management and revenues stemming from responsible product/services. It is worthwhile examining the effect of the risks and opportunities raised by Kuti (2014) on production companies, but to this end, we should switch to a stochastic model.

\section{References}

Abdullah, L. (2014): Linear Relationship between $\mathrm{CO}_{2}$ Emissions and Economic Variables: Evidence from a Developed Country and a Developing Country. Journal of Sustainable Development, Vol. 8, Issue 2: 66-72.

Barancsuk, J. (2012): Micro-economy. 2. Reviewed addition, Pécs, University of Pécs, Faculty of Business and Economics.

Benyus, J. M. (1997): Biomimicry: Innovation Inspired by Nature. New York, Harper Collins Publishers Inc.

Bessenyei, I. (2016): Vállalati stratégia a lineáris tevékenységelemzés modelljében (Business strategy in the model of linear activity and analysis of production). International Journal of Engineering and Management Sciences, 1: 1-14. https://doi.org/10.21791/IJEMS.2016.1.9.

Bocken, N.M.P. - Short, S.W. - Rana, P. - Evans, S. (2014): A Literature and Practice Review to Develop Sustainable Business Model Archetypes. Journal of Cleaner Production, Vol. 65: 42-56. https://doi.org/10.1016/j.jclepro.2013.11.039.

Brink, C. - van lerland, E. - Hordijk, L - Kroeze, C. (2001): Cost-Effective Emission Abatement in Europe. Optimizing Nitrogen Management in Food and Energy Production and Environmental Protection. Contributed papers from the 2nd International Nitrogen Conference 14-18 October 2001, Potomac, Maryland, USA. In: The Scientific World (2001) 1(S2): 814-821.https://doi.org/10.1100/tsw.2001.295.

Ding, H. - Zhao, Q - An, Z. - Xu, J. - Liu, Q. (2015): Pricing Strategy of Environmental Sustainable Supply Chain with Internalizing Externalities. International Journal Production Economics, 170: 563-575. https://doi.org/10.1016/j.ijpe.2015.05.016.

Dobos, I. (2008): Visszutas logisztika és termeléstervezés (Return logistics and production planning). Szigma, Vol. 39, 3-4: 139-167.

Esty, D. - Porter, M. (1988): Industrial Ecology and Competitiveness: Strategic Implications for the Firm. Journal of Industrial Ecology Vol. 2, No. 1: 35-43. https://doi.org/10.1162/ jiec.1998.2.1.35. 
Gao, L. - Zhao, X. (2015): Determining Intra-company Transfer pricing for Multinational Corporations. International Journal Production Economics, Vol. 168: 340-350. https:// doi.org/10.1016/j.ijpe.2015.07.006.

Genovese, A. - Acquaye, A. A. - Figueroa, A. - Koh, A. C. L. (2017): Sustainable Supply Chain Management and the Transition towards a Circular Economy: Evidence and some Applications. Omega, Vol. 66, Part B, pp. 344-357. https://doi.org/10.1016/j. omega.2015.05.015.

George, D.A.R. - Lin, B.C. - Chen, Y. (2015): A Circular Economy Model of Economic Growth. Environmental Modelling and Software, Vol. 73: 60-63. https://doi.org/10.1016/j. envsoft.2015.06.014.

Ghisellinia, P. - Cialanib, C. - Ulgiatic S. (2016): A Review on Circular Economy: the Expected Transition to a Balanced Interplay of Environmental and Economic Systems. Journal of Cleaner Production, Vol. 114: 11-32. https://doi.org/10.1016/j.jclepro.2015.09.007.

Hartung, K. (2016): Természeti környezetbe ágyazott vállalatok, és termelésük módszertani szakirodalmának áttekintése (Firms embedded into the natural environment and the review of the literature on their production methodology). Szigma, issue 1-2:63-77.

Jaehn, F. (2016): Sustainable Operations. European Journal of Operational Research, Vol. 253: 243-264. https://doi.org/10.1016/j.ejor.2016.02.046.

Karpoff, J.M. - Lott, J.R. - Rankine, G. (1998): Environmental Violations, Legal Penalties, and Reputation Costs. John M. Olin Law and Economics Working Paper No. 71., University of Chicago.

Khalili, N.R. - Duecker, S. - Ashton, W. - Chavez, F. (2015): From Cleaner Production to Sustainable Development: the Role of Academia. Journal of Cleaner Production, 96: 30-43. https://doi.org/10.1016/j.jclepro.2014.01.099.

Klemes, J. J. - Varbanov, P. S. - Huisingh, D. (2012): Recent Cleaner Production Advances in Process Monitoring and Optimization. Journal of Cleaner Production, 34: 1-8. https://doi. org/10.1016/j.jclepro.2012.04.026.

Kuti, M. (2014): A fenntarthatóság és a pénzügyek integrálhatóságának kihívásai (Challenges of sustainability and financial integration). Hitelintézeti Szemle, Vol. 13(2): 164-173.

Lakatos, M. - Karai, É. (2015): A fenntarthatóság és a pénzügyek integrálhatóságának kihívásai (Buy or sell? Hungarian carbon credit trading - learning the lesson). Pénzügyi Szemle, 3: 333-348.

Li, R.H.- Su, C.H. (2012): Evaluation of the Circular Economy Development Level of Chinese Chemical Enterprises. Procedia Environmental Sciences, 13: 1595-1601. https://doi. org/10.1016/j.proenv.2012.01.151. 
Munck, L. (2016): Sustainable Grain Production and Utilization. Encyclopedia of Food Grains (2ndedition), Vol. 4: 144-153. https://doi.org/10.1016/B978-0-12-394437-5.00204-7.

OECD (2009): Determination and Application of Administrative Fines for Environmental Offences: Guidance for Environmental Enforcement Authorities in EECCA Countries. https:// www.oecd.org/env/outreach/42356640.pdf. Downloaded: 28 October 2016.

Pauli, G. (1997): Zero Emissions: The Ultimate Goal of Cleaner Production. Journal of Cleaner Production, Vol. 5, 1-2: 109-113. https://doi.org/10.1016/S0959-6526(97)00013-9.

Pauli, G. (1998): Technology Forecasting and Assessment: The Case of Zero Emissions. Technological Forecasting and Social Change, Vol. 58, Issue 1-2: 53-68. https://doi. org/10.1016/S0040-1625(97)00055-3.

Pauli, G. (2010): A Kék Gazdaság (The Blue Economy). PTE KTK publisher.

Potting, J. - Hauschild, M. (1997): Predicted Environmental Impact and Excepted Occurrence of Actual Environmental Impact part 1: The Linear Nature of Environmental Impact from Emissions in Life-cycle Assessment. The International Journal of Life Cycle Assessment, Vol. 2, Issue 3: 171-174. https://doi.org/10.1007/BF02978815.

Schlemminger, H. - Martens, C.P. (2004): German Environmental Law for Practitioners. 2nd ed., CN The Hague, Kluwer Law International.

Wenzel, H. - Hauschild, M. - Alting, L. (1997): Environmental Assessment of Products. Volume 1: Methodology, Tools and Case Studies in Product Development. USA, Kluwer Academic Publishers.

Zalai, E. (2012): Matematikai közgazdaságtan II. - Többszektoros modellek és makrogazdasági elemzések (Mathematical economics II. - Multi-sector models and macro-economic analysis). Akadémiai Kiadó, Budapest. 


\section{Appendix}

Simplex table necessary for formulating the dual problem of firms striving to minimize negative environmental impact:

\begin{tabular}{c|ccccc|cc} 
& $\mathbf{x}$ & $\mathbf{s}$ & $\mathbf{u}$ & $\mathbf{z}$ & $\mathbf{y}^{\mathbf{p}}$ & & \\
\hline $\mathbf{p}$ & $-(\mathbf{K}-\mathbf{R})$ & 0 & $-\mathbf{E}$ & $\mathbf{E}$ & $\mathbf{E}$ & $=$ & $-\mathbf{y}$ \\
$\mathbf{w}$ & $\mathbf{D}$ & $-\mathbf{E}$ & 0 & 0 & 0 & $\leq$ & $\overline{\mathbf{s}}$ \\
$v$ & 0 & 0 & $\mathbf{p}^{\mathrm{m}}$ & $-\mathbf{p}^{\mathrm{e}}$ & 0 & $\leq$ & $d_{e}$ \\
$\mathbf{t}^{y}$ & 0 & 0 & 0 & 0 & $\mathbf{E}$ & $\leq$ & $\overline{\mathbf{y}}$ \\
& $\geq$ & $\geq$ & $\geq$ & $\geq$ & $\geq$ & & \\
\hline & 0 & $-\mathbf{q}$ & 0 & 0 & 0 & &
\end{tabular}

Simplex table necessary for formulating the dual problem of the quasi blue economy type of firm:

\begin{tabular}{c|ccccc|cc} 
& $\mathbf{X}$ & $\mathbf{s}$ & $\mathbf{u}$ & $\mathbf{z}$ & $\mathbf{y}^{\mathbf{p}}$ & & \\
\hline $\mathbf{p}$ & $-(\mathbf{K}-\mathbf{R})$ & 0 & $-\mathbf{E}$ & $\mathbf{E}$ & $\mathbf{E}$ & $=$ & $-\mathbf{y}$ \\
$\mathbf{w}$ & $\mathbf{D}$ & $-\mathbf{E}$ & 0 & 0 & 0 & $\leq$ & $\overline{\mathbf{s}}$ \\
$v$ & 0 & 0 & $\mathbf{p}^{\mathrm{m}}$ & $-\mathbf{p}^{\mathbf{e}}$ & 0 & $\leq$ & $\mathbf{d}_{\mathbf{e}}$ \\
& $\geq$ & $\geq$ & $\geq$ & $\geq$ & $\geq$ & &
\end{tabular}

